\title{
Voltage-Integral-based Reference Tracking Modulation Method for High-Efficiency Motor Drive
}

\author{
Yuto Kobayashi* \\ Yuki Yokokura* \\ Akira Satake**
}

\author{
Student Member,
}

Member,

Member

\author{
Kiyoshi Ohishi* \\ Fellow \\ Tenjiro Hiwatari** Member
}

This paper focuses on the voltage modulation method to reduce the switching frequency and proposes a voltageintegral-based reference tracking modulation (VIRTM) method. The proposed method calculates an evaluation function by considering the factors of the switching frequency. Thereafter, the proposed method outputs the voltage vector based on the evaluation function and reduces the switching frequency. The switching frequency of the conventional discontinuous pulse width modulation (DPWM) and that of the proposed VIRTM are evaluated by using simulations and experiments based on feed-forward and feedback control systems. From the results, the usefulness and effectiveness of the proposed method are confirmed.

Keywords: Voltage-integral-based reference tracking modulation, Switching frequency reduction, Discontinuous pulse width modulation, Delta sigma modulation, Two-level three-phase voltage source inverter

\section{Introduction}

In various industrial drives, simple pulse width modulation (PWM) method is useful and effective because the modulation does not require motor and controller parameters. With this motivation and background, the carrier comparison modulation (CCM) method has been widely used ${ }^{(1) \sim(5)}$. CCM modulates the voltage reference regardless of motor parameters and specifications of the control system. Therefore, it is effective for a variety of applications including motor drives. Moreover, the system requires a method with lower switching frequency compared to the conventional CCM to save energy, size, and weight.

However, the conventional CCM is not effective for reducing the switching frequency because the switching frequency is determined by the carrier frequency. To reduce the switching frequency in $\mathrm{AC}$ motor drives, discontinuous PWM (DPWM) method has been proposed ${ }^{(6)}$, which is one of CCM methods. DPWM always provides a halting period in one of the three phases by manipulating the zero-phase component. Thus, DPWM reduces the switching frequency to two-third and achieves lower switching frequency than the conventional CCM. However, the switching frequency of DPWM is also determined by the carrier frequency and DPWM is not optimized for the switching frequency.

Furthermore, the delta sigma modulation (DSM) method has been used in similar applications as $\mathrm{CCM}^{(7)(8)}$. DSM integrates the voltage error and controls the voltage integral error to be less than a predetermined value. DSM has variable switching frequency unlike CCM and this feature is useful

\footnotetext{
* Motion Control Lab., Nagaoka University of Technology,

1603-1, Kamitomioka, Nagaoka, Niigata, Japan 940-2188

** Mitsubishi Electric Corp., 8-1-1, Tsukaguchi-honmachi,

Amagasaki, Hyogo, Japan, 661-8661
}

for reducing switching frequency. However, DSM modulates each voltage reference of the three phases independently in the motor drives. As an advanced DSM method, the vector DSM (VDSM) ${ }^{(9) \sim(1)}$ method has been proposed. VDSM is effective for motor drives by handling the voltage integral error vector, which is the composition of voltage integral error of each phase. The general VDSM method has an allowance of voltage integral error, called hysteresis band. VDSM determines the switching state to minimize the error of voltage integral when the voltage integral error vector exceeds the hysteresis band ${ }^{(9)(10)}$. The hysteresis band eliminates the voltage output with a short duration and VDSM achieves a switching frequency reduction. However, VDSM does not handle the switching frequency because the switching state minimizing the error of voltage integral is computed by only the phase and amplitude of the voltage integral error vector. Therefore, VDSM does not optimize the switching frequency.

A Model Predictive Control (MPC) ${ }^{(12) \sim(16)}$ method which directly considers the switching frequency has been proposed as a torque or current controller for motor drives. MPC predicts the motor responses based on the motor model and each state. MPC decides the voltage output based on the evaluation function, which is defined for variable requirements. Regarding an MPC, which aims to reduce the switching frequency, the evaluation function normally includes the switching frequency. Therefore, MPC optimizes the switching frequency directly unlike CCM and DSM. However, the application of MPC is limited because MPC is not a modulator. Therefore, MPC is used only in feedback control systems for high efficiency and high performance.

This paper focuses on a simple voltage modulation method for high-efficiency inverter control, which is independent of the motor parameters and control system characteristics. This high-efficiency inverter control contributes to minimizing the 
size and weight of the inverter, and this paper aims at this requirement. For this reason, this paper focuses on the performance under the high-load condition where the heat generation of the inverter is high. This paper also proposes a modulation method that solves these problems, such as indirect switching frequency optimization and the limitation of applications. The conventional DPWM has excellent versatility and reduces the switching frequency. Therefore, this paper evaluates the proposed method by comparing the conventional DPWM. In this paper, the proposed method and conventional method are discussed as general-purpose motor drives in steady state. Furthermore, this paper discusses both methods in linear modulation region instead of in overmodulation region. This paper clarifies the effectiveness of the proposed method in feed-forward and feedback control systems by using two controllers. One of the controllers is the $\mathrm{V} / \mathrm{f}$ controller, which has a constant voltage reference, as a feed-forward control system. Another one of the controllers is the velocity controller, which has variable voltage reference, as a feedback control system. This paper confirms the usefulness and effectiveness of the proposed modulation method through theoretical analysis and experimental results.

\section{Characteristics of Carrier Comparison Modu- lation}

This paper remarks on the operation principle of DPWM and confirms its features. Based on the features, this section discusses the factors for reducing the switching frequency.

2.1 Carrier Comparison Modulation Fig. 1 shows the carrier comparison operation and generated gate signal by CCM. In Fig. 1, the symbol $\Theta, \theta_{e}$, and the subscript ${ }_{M}$ denote the switching angle, electric angle, and the number of switchings in a cycle, respectively. The voltage reference is normalized by $V_{d c} / 2$ and $V_{d c}$ denotes the DC-link voltage. The gate signal is generated by the operation of carrier comparison. Voltage output is considered by using the switching angle $\Theta$ and the voltage output $v^{\text {out }}$ is given by a Fourier series expansion as

$$
\begin{aligned}
& v^{\text {out }}=a_{o}+\sum_{N=0}^{\infty} \sqrt{a_{N}^{2}+b_{N}^{2}} \sin \left\{N \theta_{e}+\arctan \left(\frac{a_{N}}{b_{N}}\right)\right\}, \\
& a_{0}=\frac{1}{\pi}\left(\pi+\sum_{i=1}^{M}(-1)^{i+1} \Theta_{i}\right) \text {, } \\
& a_{N}=\frac{2}{N \pi}\left(\sum_{i=1}^{M}(-1)^{i+1} \sin N \Theta_{i}\right) \text {, } \\
& b_{N}=\frac{2}{N \pi}\left(\sum_{i=1}^{M}(-1)^{i} \cos N \Theta_{i}\right) \text {, }
\end{aligned}
$$

where $N$ denotes the number of harmonic orders.

2.2 Physical Meaning of Voltage Integral Error In general, the integral of voltage error is regarded as an index of the voltage total harmonic distortion (THD) ${ }^{(17)}$. When the fundamental element of voltage reference $v^{\text {ref }}$ and voltage output $v^{\text {out }}$ are assumed to match, the voltage error $v^{e r r}$ is expressed as

$$
v^{e r r}=v^{r e f}-v^{\text {out }}
$$

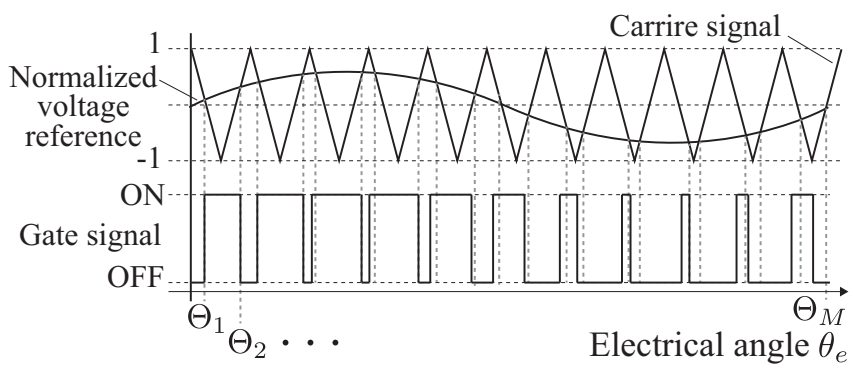

Fig. 1. Carrier comparison operation and generated gate signal by CCM.

$$
=\sum_{N=2}^{\infty} \sqrt{a_{N}+b_{N}} \sin \left\{N \theta_{e}+\arctan \left(\frac{a_{N}}{b_{N}}\right)\right\} . \cdots
$$

Therefore, the voltage error implies all voltage harmonics. To consider the voltage error vector in two-phase stationary coordinates ( $\alpha \beta$-coordinate), the voltage error vector is decomposed as

$$
\begin{aligned}
\boldsymbol{v}_{\alpha \beta}^{\text {err }}= & v_{\alpha}^{\text {err }}+\boldsymbol{j} v_{\beta}^{\text {err }} \cdots \cdots \cdots \cdots \cdots \cdots \cdots \cdots \cdots \cdots(7) \\
= & \sum_{N=2}^{\infty} \sqrt{a_{N}+b_{N}} \sin \left\{N \theta_{e}+\arctan \left(\frac{a_{N}}{b_{N}}\right)\right\} \\
& \quad-\boldsymbol{j} \sum_{N=2}^{\infty} \sqrt{a_{N}+b_{N}} \cos \left\{N \theta_{e}+\arctan \left(\frac{a_{N}}{b_{N}}\right)\right\}(8) \\
\equiv & \sum_{N=2}^{\infty} P_{N} \sin \left(\chi_{N}\right)-j \sum_{N=2}^{\infty} P_{N} \cos \left(\chi_{N}\right), \cdots \cdots \cdots(9) \\
& \because\left\{\begin{array}{l}
P_{N}=\sqrt{a_{N}+b_{N}} \\
\chi_{N}=N \theta_{e}+\arctan \left(\frac{a_{N}}{b_{N}}\right) \quad, \cdots \cdots \cdots(10)
\end{array}\right.
\end{aligned}
$$

where $P_{N}$ and $\chi_{N}$ denote the amplitude and phase of the voltage error, respectively. Here, the integral of this voltage error vector $\int \boldsymbol{v}_{\alpha \beta}^{e r r} \mathrm{~d} t$ is expressed as

$$
\begin{aligned}
\int_{-\pi}^{\pi}\left|\boldsymbol{v}_{\alpha \beta} \boldsymbol{e r r}\right|^{2} \mathrm{~d} \theta_{e}= & \int_{-\pi}^{\pi} \sum_{N=2}^{\infty} P_{N}^{2} \sin ^{2}\left(\chi_{N}\right) \mathrm{d} \theta_{e} \\
& \quad-\boldsymbol{j} \int_{-\pi}^{\pi} \sum_{N=2}^{\infty} P_{N}^{2} \cos ^{2}\left(\chi_{N}\right) \mathrm{d} \theta_{e} . \\
& =\sum_{N=2}^{\infty} P_{N}^{2} . \ldots \ldots \ldots \ldots \ldots \ldots \ldots
\end{aligned}
$$

Thus, the integral of the voltage error implies the voltage THD in a cycle. The voltage THD in the period from $t$ to $t+\Delta t$ is also calculated by the time integral of the voltage error.

2.3 Discontinuous Pulse Width Modulation To confirm the effect of the gate signal with a short duration, this part simulates DPWM which is a CCM method. In this paper, as the simulation and experimental setup, an induction motor (IM) is used as the controlled motor, and an interior permanent magnet synchronous motor (IPMSM) is used to act on the load environment. Between each motor, a torque meter is positioned to measure the torque responses. The parameters of tested IM are listed in Table 1. The system is illustrated in Fig. 2. Here, the generated gate signal drives 
Table 1: Parameters of tested IM.

\begin{tabular}{cc|rl}
\hline \hline Parameter & Symbol & Specification & Unit \\
\hline \hline rated output & $P_{R}$ & 2200 & $\mathrm{~W}$ \\
\hline $\begin{array}{c}\text { rated angular } \\
\text { velocity }\end{array}$ & $\omega_{r m, R}$ & 1745 & $\mathrm{r} / \mathrm{min}$ \\
\hline rated torque & $T_{R}$ & 12.0 & $\mathrm{Nm}$ \\
\hline stator resistor & $R_{s}$ & 0.411 & $\Omega$ \\
\hline rotor resistor & $R_{r}$ & 0.382 & $\Omega$ \\
\hline stator inductor & $L_{s}$ & 90.5 & $\mathrm{mH}$ \\
\hline rotor inductor & $L_{r}$ & 90.5 & $\mathrm{mH}$ \\
\hline mutual inductor & $M$ & 86.7 & $\mathrm{mH}$ \\
\hline number of pole pairs & $p$ & 2 & \\
\hline \hline
\end{tabular}

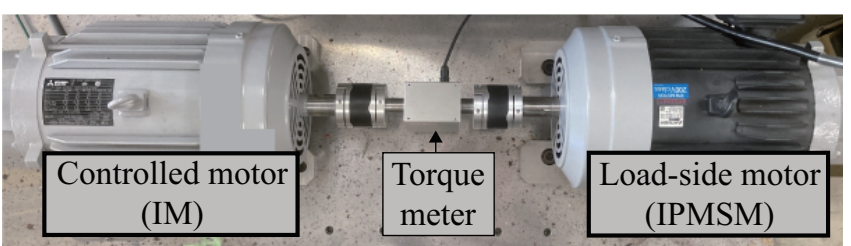

Fig. 2. Experimental setup.

the switching element $S_{u v w,+-}$ of the inverter shown in Fig. 3 (a), and by the switching operation, the voltage output $v_{u v w}^{\text {out }}$ is determined. In general, each switching state generates a unique voltage output in $\alpha \beta$-coordinate, which is expressed as a voltage vector $V_{n},(n=0-7)$, as shown in Fig. 3 (b). Regarding the three numbers $(u, v, w)$ next to the voltage vectors, 0 and 1 express $\left\{S_{+}, S_{-}\right\}=\{0,1\}$ and $\{1,0\}$, respectively.

Figs. 4 and 5 show the simulation results of DPWM. In this simulation, the carrier frequency $f_{\text {car }}$ is set to $2.0 \mathrm{kHz}$ and $50 \%$ rated torque is loaded. The modulation factor is set to 0.8 .

Fig. 4 shows the time responses of DPWM. By the DPWM method, one of three phases of the switching element is halted. Therefore, DPWM outputs two non-zero voltage vectors and only one zero voltage vector in a carrier cycle. This operation contributes to the switching frequency reduction comparing with CCM.

Fig. 5 shows the voltage integral responses. This figure is drawn with the approximate origin $O$ of the voltage integral locus as the center. The references $\int v^{r e f} \mathrm{~d} t$ and outputs $\int v^{\text {out }} \mathrm{d} t$ of voltage integral match per carrier cycle. The results also verify that DPWM outputs two non-zero voltage vectors and one zero voltage vector in a carrier cycle.

2.4 Problem Formulation According to Eqs. 3 and 4, two adjacent switching angles scarcely affect the voltage output when these switching angle values are similar. In the case of switching angles $\Theta_{I}$ and $\Theta_{J}$ being close, Eqs. 3 and 4 are calculated as

$$
\begin{aligned}
& a_{N}=\frac{2}{N \pi}\left(\sin N \Theta_{1}-\sin N \Theta_{2}+\cdots+\sin N \Theta_{I}-\sin N \Theta_{J}\right. \\
& \left.+\cdots-\sin N \Theta_{M}\right) \\
& =\frac{2}{N \pi}\left(\sin N \Theta_{1}-\sin N \Theta_{2}+\cdots+\underline{\sin N \Theta_{I}}-\underline{\sin N \Theta_{J}}\right. \\
& \left.+\cdots-\sin N \Theta_{M}\right)\left.\right|_{\Theta_{I} \doteqdot \Theta_{J}}, \\
& b_{N}=\frac{2}{N \pi}\left(-\cos N \Theta_{1}+\cos N \Theta_{2}-\cdots-\cos N \Theta_{I}+\cos N \Theta_{J}\right. \\
& \left.-\cdots+\cos n \Theta_{M}\right) \\
& =\frac{2}{N \pi}\left(-\cos N \Theta_{1}+\cos N \Theta_{2}-\cdots-\cos N \Theta_{I}+\cos N \Theta_{J}\right.
\end{aligned}
$$

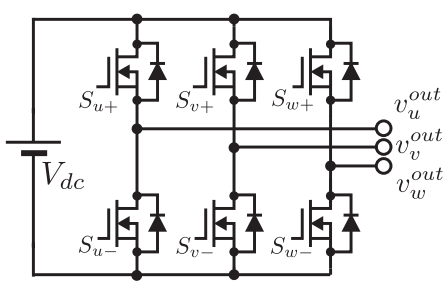

(a) Two-level three-phase voltage source inverter

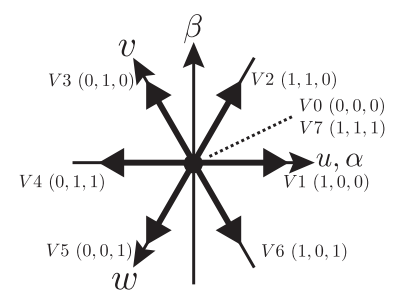

(b) Number of voltage vector
Fig. 3. Tested inverter model and voltage vector definition.

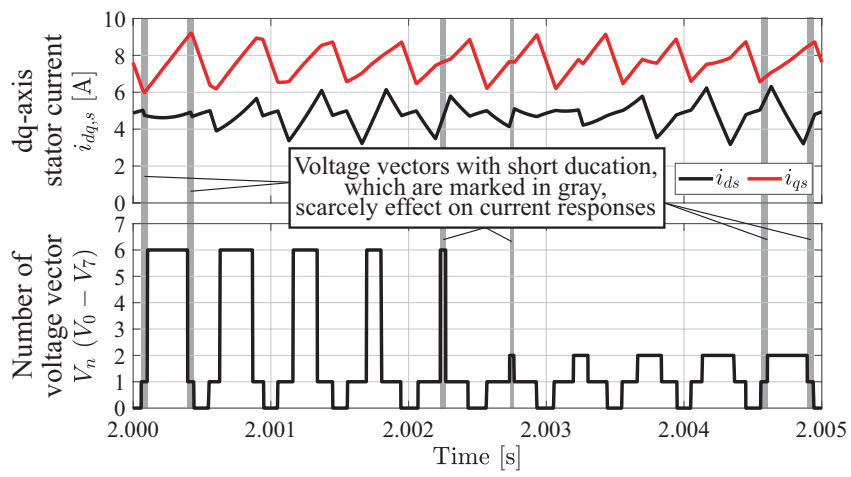

Fig. 4. Numerical simulation results of current responses and number of outputted voltage vector of DPWM on condition of modulation factor $=0.8$ and half load torque.

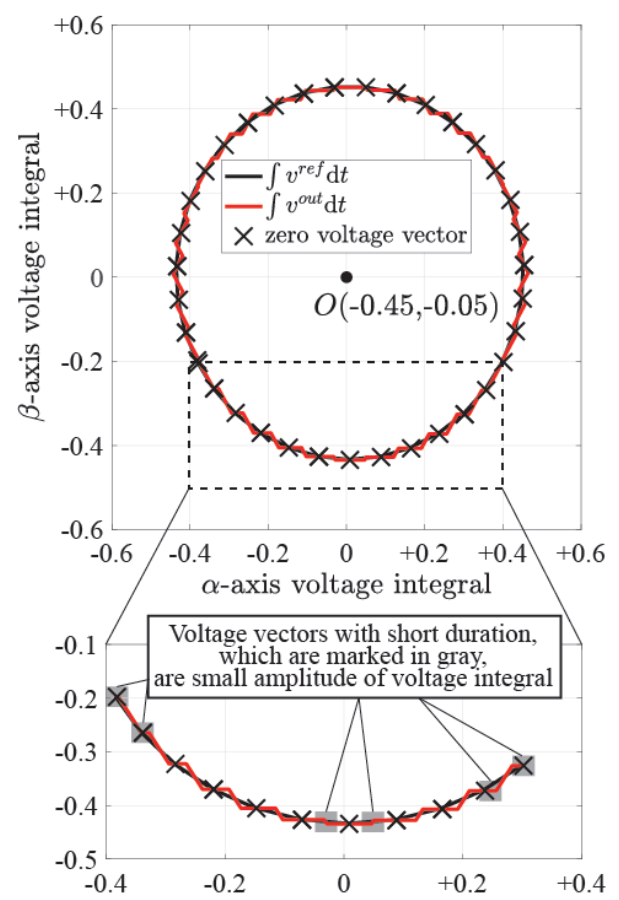

Fig. 5. Numerical simulation results of voltage integral locus of DPWM on condition of modulation factor $=0.8$ and half load torque.

$$
\left.-\cdots+\cos N \Theta_{M}\right)\left.\right|_{\Theta_{I} \doteqdot \Theta_{J}} .
$$

Therefore, these switching angles are canceled even though they cause an increase in the switching frequency. This phenomenon suggests that the gate signal output with a short duration is inefficient for reducing the switching frequency.

Numerical simulation results of DPWM also demonstrate this phenomenon. The current responses illustrated in Fig. 4 
— voltage vectors with a short duration that are marked in gray - have a negligible effect on current responses. Moreover, Fig. 5 shows that the voltage integral output is changed frequently when DPWM outputs voltage vectors with short duration. In this situation, the change in the voltage THD is negligible because the change of the integral of voltage error is small.

Therefore, voltage vectors having a short duration cause inefficient switching. The carrier comparison does not eliminate these voltage vectors.

\section{Voltage-Integral-based Reference Tracking Modulation}

3.1 Approach for the DPWM Problem The switching frequency is related to a trade-off relation with the current THD, as illustrated in Fig. 6. The switching frequency is decided by two factors, namely the switching count and duration, as depicted on the left of Fig. 6. When the voltage vector with a long duration is output, the switching frequency is small. However, given the trade-off relation between the switching frequency and the current THD, a large current distortion results also. Therefore, the method requires a rough current distortion limit to be considered for use in applications.

MPC, which uses an evaluation function, is considered as an approach for reducing the switching frequency. Traditional MPCs, such as model predictive-based direct torque control and model predictive-based direct current control, have hysteresis bands to set the maximum current ripple or torque ripple. Owing to this hysteresis band, the MPCs achieve switching frequency reduction, thereby limiting the ripples. However, the modulation method considered in this paper does not directly handle the current distortion shown on the right of Fig. 6. Therefore, the modulation method controls the voltage integral output to follow the voltage integral reference. Since the integral of the voltage error implies the voltage THD, the maximum value of the voltage integral error is regulated by the hysteresis band to roughly limit the current distortion. This paper proposes voltage-integralbased reference tracking modulation (VIRTM) as a simple voltage modulation method for high-efficiency inverter control.

\subsection{Applying Hysteresis Band to Voltage Modulation}

Since the proposed method is a modulator, the proposed method does not observe the current responses, unlike traditional MPCs. Thus, the proposed method handles the voltage integral. This voltage integral reference $\int v^{r e f} \mathrm{~d} t$ is expressed by using the voltage reference $v^{r e f}$ as

$$
\begin{aligned}
& \int v^{r e f}(t) \mathrm{d} t=\lim _{\Delta t \rightarrow 0} \sum_{n=0}^{\infty} v^{r e f}[n] \Delta t, \\
\therefore \quad & \int_{0}^{k T_{s}} v^{r e f} \mathrm{~d} t=T_{s} \sum_{n=0}^{k} v^{r e f}[n], \cdots
\end{aligned}
$$

where $n$ and $T_{s}$ denote the sampling number and sampling time, respectively. In steady state, $v^{\text {ref }}$ is expressed as

$$
\begin{aligned}
v^{r e f}(t) & =V^{r e f} \cos \left(\theta_{e}(t)\right) \ldots \ldots \\
& =V^{r e f} \cos \left(\omega_{e} t+\theta_{e}(0)\right)
\end{aligned}
$$

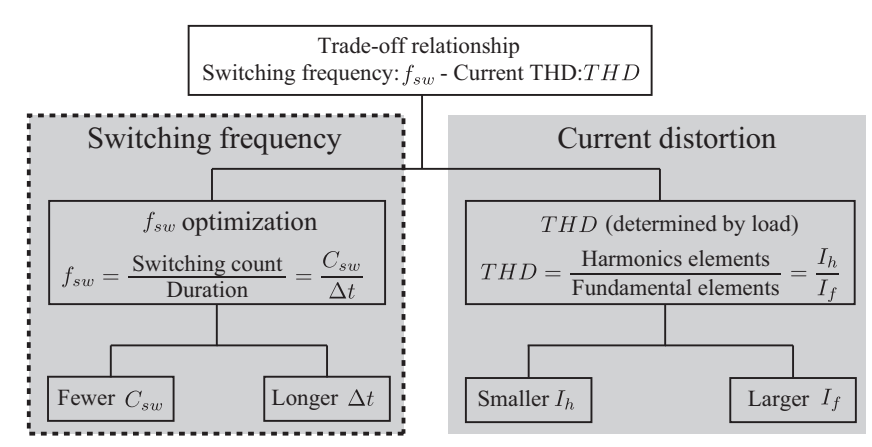

Fig. 6. Factors of trade-off between switching frequency and current THD.

$$
\therefore v^{r e f}[k]=V^{r e f} \cos \left(\omega_{e} k T_{s}+\theta_{e}[0]\right),
$$

where $V^{r e f}, \theta_{e}$, and $\omega_{e}$ denote the amplitude, angle, and the angular velocity of the voltage reference, respectively. These parameters are lead by two voltage references $v^{r e f}[k]$ and $v^{r e f}[k-1]$. By using the voltage output $v^{\text {out }}$, the voltage integral output $\int v^{\text {out }} \mathrm{d} t$ is also calculated as

$$
\begin{aligned}
\int v^{\text {out }}(t) \mathrm{d} t & =\lim _{\Delta t \rightarrow 0} \sum_{n=0}^{\infty} v^{\text {out }}[n] \Delta t, \\
\therefore \int_{0}^{k T_{s}} v^{\text {out }} \mathrm{d} t & =T_{s} \sum_{n=0}^{k} v^{\text {out }}[n] . \cdots
\end{aligned}
$$

$v^{\text {out }}$ is determined from the switching states of the inverter by using the DC-link voltage $V_{d c}$. The voltage output is estimated as $v^{\text {out }}$ and expressed as

$$
v^{\text {out }}(t)=C S[k]^{T} V_{u v w}^{\text {out }},
$$

where $\boldsymbol{C}, \boldsymbol{S}$, and $V_{u v w}^{\text {out }}$ denote the transformation matrix, switching state matrix, and voltage output on three-phase, respectively. When $v^{\text {out }}$ is handled in $\alpha \beta$-coordinates, $\boldsymbol{C}$ is expressed as

$$
C=\sqrt{\frac{2}{3}}\left[\begin{array}{ccc}
1 & -1 / 2 & -1 / 2 \\
0 & \sqrt{3} / 2 & -\sqrt{3} / 2
\end{array}\right] .
$$

The voltage output of three-phase $V_{u v w}^{\text {out }}$ is shown as

$$
V_{u v w}^{\text {out }}=\frac{V_{d c}}{2} .
$$

The proposed method considers the influence of dead time and on-voltage drop by modifying $V_{u v w}^{\text {out }}$.

The voltage integral output is calculated by using only the $V_{d c}$ feedback. The hysteresis band $\Delta \int v \mathrm{~d} t$ is set as the amplitude of the voltage integral error vector by following Eq. 12. The voltage integral error is calculated by using from Eq. 18 and Eq. 23 as

$$
\int_{0}^{k T_{s}} v^{e r r} \mathrm{~d} t=\int_{0}^{k T_{s}} v^{r e f} \mathrm{~d} t-\int_{0}^{k T_{s}} v^{\text {out }} \mathrm{d} t .
$$

To keep the maximum value of the voltage integral error, the proposed method changes the switching state when the following equation is established:

$$
\Delta \int v \mathrm{~d} t<\left|\int \boldsymbol{v}_{\alpha \beta}^{e r r} \mathrm{~d} t\right|
$$




$$
<\sqrt{\left(\int v_{\alpha}^{e r r} \mathrm{~d} t\right)^{2}+\left(\int v_{\beta}^{e r r} \mathrm{~d} t\right)^{2}} \cdots \cdots \cdot
$$

This operation principle contributes to being a long duration of outputting voltage vector while the voltage integral output follows the voltage integral reference. Therefore, the proposed method eliminates the voltage vector output with a short duration which is inefficient. This operation collectively outputs some voltage vectors with short duration as a voltage vector with a long duration. Thus, the utilization of the maximum voltage output is the same as the inverter's voltage output limitation, similar to SVM and DPWM.

3.3 Design Criteria of Proposed Switching Selection

The duration $n T_{s}$ which is the time from $k$ to $k+n$ and switching count $C_{s w}$ construct the switching frequency. Thus, the evaluation function $J$ considers both factors and is expressed as

$$
\begin{aligned}
J & =\frac{C_{s w}}{T_{s}}, \ldots \ldots \ldots \ldots \ldots \\
\therefore J[k] & =\frac{C_{s w}(\boldsymbol{S}[k+n], S[k])}{T_{s}},
\end{aligned}
$$

where $C_{s w}(S[k+n], S[k])$ is the switching counts from $S[k]$ to $S[k+n]$. The proposed method calculates the evaluation function of each voltage vector. Thereafter, the proposed method selects a voltage vector which has a minimum value of the evaluation function. This operation contributes to reducing the switching frequency.

Fig. 7 shows the image of the voltage vector selection of VIRTM by using the evaluation function. The figure depicts the voltage integral reference, output, and error at sampling time $k$. In this situation, the inverter outputs $V_{0}$ and Eq. 29 is established. During the operation of the voltage vector selection, VIRTM predicts each voltage integral output sequentially, on the basis of the assumption that the inverter outputs voltage vectors $V_{1}-V_{6}$ by using this sampling time. Simultaneously, VIRTM also predicts the voltage integral reference and calculates Eq. 29 by using each voltage vector at each sample. This calculation yields the number of samples $n$ for each voltage vector. These predictions are calculated until all the voltage vectors satisfy Eq. 29 or the operation is terminated owing to the control period. VIRTM calculates the duration of each voltage vector on the basis of the calculated $n$. In contrast, the number of switching count $C_{s w}$, for the transition from the current voltage vector to each voltage vector, is also calculated. VIRTM calculates the evaluation function of each voltage vector from the duration and switching count. The minimize evaluation function implies that the switching frequency is also minimized. Therefore, VIRTM selects the voltage vector with the smallest evaluation function. In the situation shown in Fig. 7, where $n_{2}>2 n_{1}$, VIRTM selects $V_{2}$ which has the smallest evaluation function. Fig. 8 shows the block diagram of the proposed method.

3.4 Operation verification of VIRTM Figs. 9 and 10 show simulated results of VIRTM. Fig. 9 shows time responses of each state and Fig. 10 shows the voltage integral locus. In this simulation, 50\% rated torque is loaded and the modulation factor is 0.8 . Here, the hysteresis band of voltage integral $\Delta \int v \mathrm{~d} t$ is set to $10 \mathrm{e}^{-3}$. Based on the results, the proposed method scarcely outputs the voltage vector with short

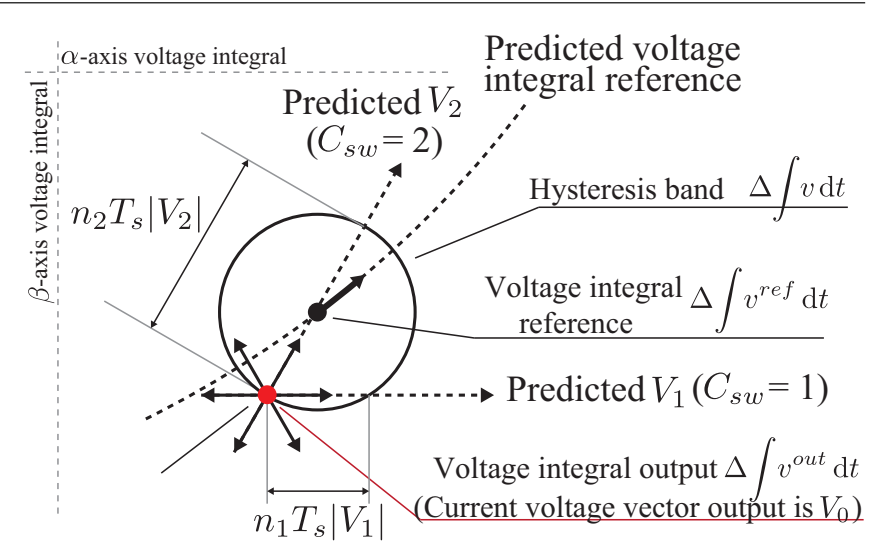

Fig. 7. Principle of voltage vector selection of VIRTM.

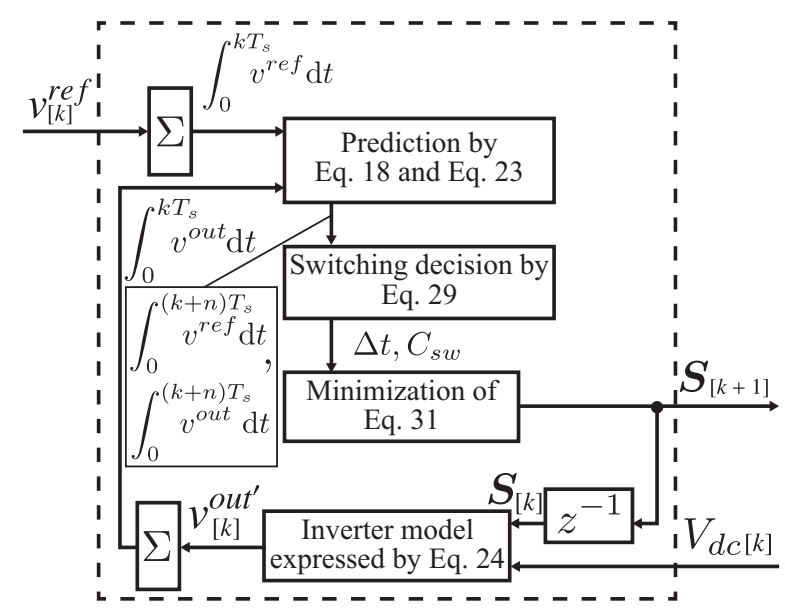

Fig. 8. Calculation flow of switching state of VIRTM.

duration and the proposed method is efficient. Moreover, the operation of the proposed method is confirmed that the voltage integral error is less than the hysteresis band. Regarding the voltage integral locus marked in gray, the inverter generally outputs two non-zero voltage vectors. One of them is the non-zero voltage vector with long duration and another one of them is the non-zero voltage vector with short duration. From the simulation results of voltage integral locus, the proposed method mainly outputs one non-zero voltage vector with long duration in that area. Thus, the proposed method eliminates the voltage vector with short duration, and the proposed method realizes the switching frequency reduction.

\section{Experiment}

4.1 Comparison Condition This paper evaluates the switching frequency of VIRTM by comparing with that of DPWM. This paper calculates the switching frequency $f_{s w}$ as the average switching count in $1 \mathrm{~s}$. Also, this paper calculates the current THD which is positioned in the trade-off relationship of switching frequency. Fig. 11 shows the spectrum of the u-phase current using DPWM. The spectrum of DPWM concentrates in the sideband of the carrier. In contrast, Fig. 12 shows the spectrum of the u-phase current using VIRTM, and its spectrum spreads over a wide frequency range. Hence, this paper calculates the current THD to consider all frequency components as 


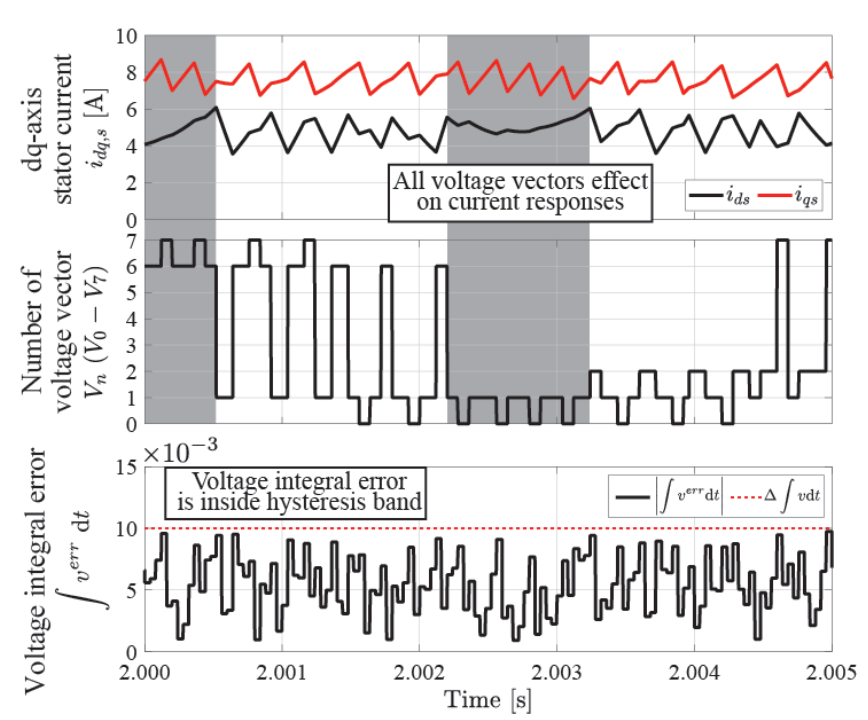

Fig. 9. Numerical simulation results of current responses, number of outputted voltage vector, and amplitude of voltage integral error of VIRTM on condition of modulation factor $=$ 0.8 and half load torque.

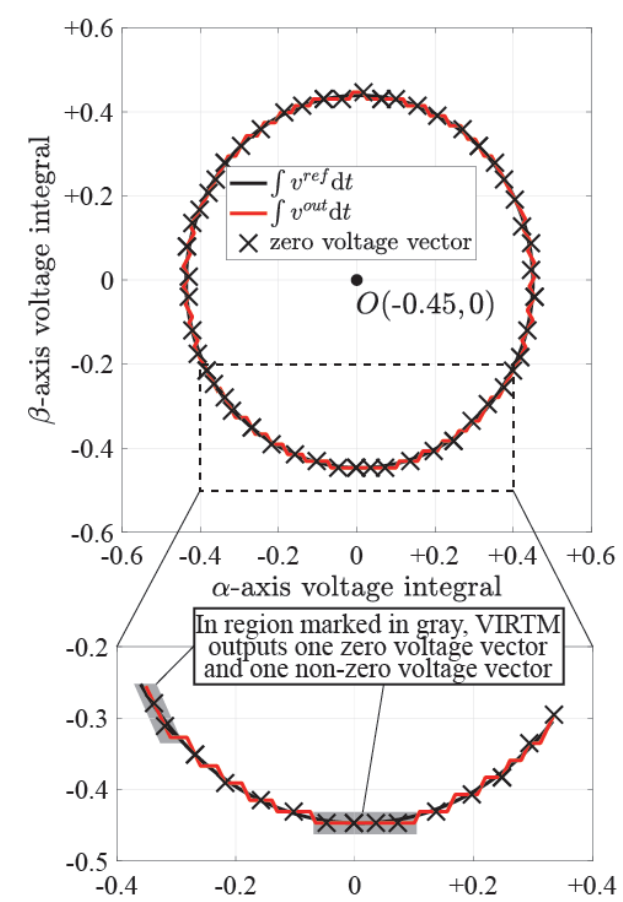

Fig. 10. Numerical simulation results of voltage integral locus of VIRTM on condition of modulation factor $=0.8$ and half load torque.

$$
T H D=\frac{\sqrt{\sum_{n=0}^{k} I_{n}^{2}-I_{f n d}^{2}}}{\sqrt{I_{f n d}^{2}}}, \cdot
$$

where $I_{n}$ and the subscript ${ }_{f n d}$ indicate the current amplitude of the frequency component at $f=n f_{r s l}$ and the fundamental component, respectively. The symbol $f_{r s l}$ denotes the frequency resolution of the current sampling.

Table 2 lists the parameters of the oscilloscope used for sampling current responses. This paper evaluates current re-

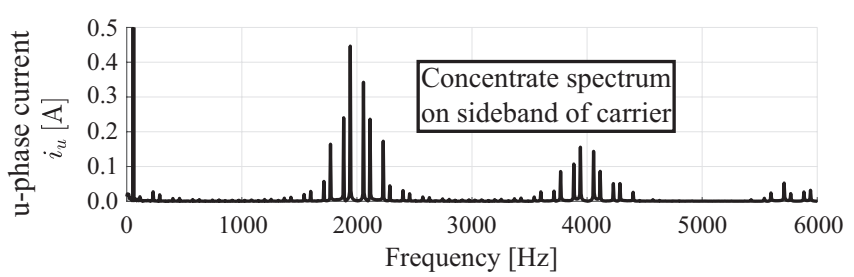

Fig. 11. Numerical simulation results of frequency responses of DPWM on condition of modulation factor $=0.8$ and half load torque.

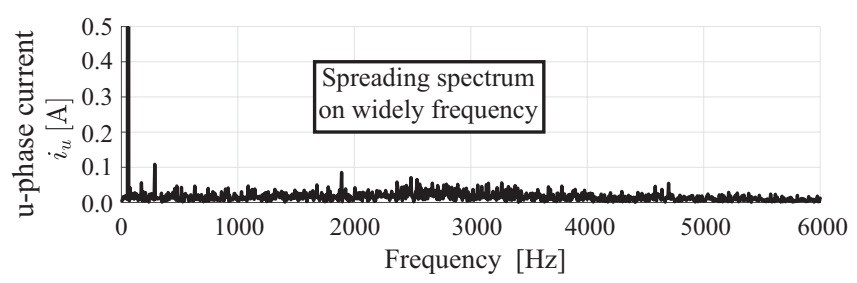

Fig. 12. Numerical simulation results of frequency responses of VIRTM on condition of modulation factor $=0.8$ and half load torque.

Table 2: Specifications of tested oscilloscope.

\begin{tabular}{cc|rc}
\hline \hline Parameter & Symbol & Specification & Unit \\
\hline \hline sampling frequency & $f_{o s c}$ & 50 & $\mathrm{MHz}$ \\
\hline frequency resolution & $f_{r s l}$ & $f_{o s c} / 2=25$ & $\mathrm{MHz}$ \\
\hline \hline
\end{tabular}

sponses in 10 fundamental cycles sampled by the oscilloscope. The controller and modulator are implemented in Expert4 developed by Myway Plus Corporation. Regarding the inverter, a SiC inverter (MWINV-1044-SiC) is used. Table 3 lists the specifications of the inverter and modulators. The experiments in this paper are conducted around the rated operation, and the dead time has little effect on the performance of both modulation methods under these experimental conditions. For this reason, this paper handles the voltage output $V_{u v w}^{\text {out }}$ as $\frac{V_{d c}}{2}$, not considering the influence of dead time and on-voltage drop. Regarding the hysteresis band set in the experiments, the hysteresis band is adjusted by trial and error such that the current THD of the current response of VIRTM is similar to that of DPWM.

4.2 Feed-Forward Control System This section confirms the effectiveness of VIRTM for reducing the switching frequency in experiments. Fig. 13 shows a block diagram of the V/f control system. This controller is used as a feedforward control system. In this comparison, the modulation factor $m$ determines the gain parameter $K_{v f}$ and the gain $K_{v f}$ is calculated as

$$
K_{v f}=\frac{1}{\sqrt{2}} \frac{V_{d c}}{\omega_{e}^{r e f}} \cdot m
$$

Table 4 lists the operating conditions of the V/f control system. In this comparative experiment, the parameters $f_{c a r}$ of DPWM and $\Delta \int v \mathrm{~d} t$ of VIRTM are changed to investigate the switching frequency. The modulation factor is set to unity, which is the maximum amplitude of the linear region. The primary angular velocity reference is set to the rated value, $360 \mathrm{rad} / \mathrm{s}$.

Fig. 14 shows the experimental results of DPWM and VIRTM on the condition of V/f control and in the current 
Table 3: Specifications of tested inverter.

\begin{tabular}{cc|rl}
\hline \hline Parameter & Symbol & Specification & Unit \\
\hline \hline DC link voltage & $V_{d c}$ & 282 & $\mathrm{~V}$ \\
\hline voltage resolution & $T_{r s l}$ & 4 & $\mathrm{~ns}$ \\
\hline dead time & $T_{\text {dead }}$ & 300 & $\mathrm{~ns}$ \\
\hline \hline control period of DPWM & $T_{c}$ & $1 / f_{c a r}$ & $\mathrm{~s}$ \\
\hline sampling period of DPWM & $T_{s}$ & $T_{c} / 10$ & $\mathrm{~s}$ \\
\hline carrier frequency & $f_{c a r}$ & $1.6-3.0$ & $\mathrm{kHz}$ \\
\hline \hline control period of VIRTM & $T_{c}$ & 40 & $\mu \mathrm{s}$ \\
\hline sampling period of VIRTM & $T_{s}$ & 40 & $\mu \mathrm{s}$ \\
\hline hysteresis band in Voltage integral & $\Delta \int v \mathrm{~d} t$ & $8.0-15.0$ & $\times 10^{-3}$ \\
\hline \hline
\end{tabular}

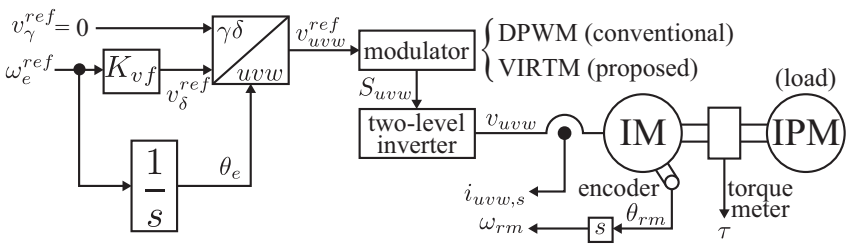

Fig. 13. Block diagram of V/f control.

Table 4: Operation condition for V/f control.

\begin{tabular}{cc|rl}
\hline \hline Parameter & Symbol & Specification & Unit \\
\hline \hline primary angular velocity reference & $\omega_{e}^{\text {ref }}$ & 360 & $\mathrm{rad} / \mathrm{s}$ \\
\hline modulation factor & $m$ & 1.0 & \\
\hline $\mathrm{V} / \mathrm{f}$ Gain & $K_{v f}$ & $0.553 \ldots$ & $\mathrm{V} /(\mathrm{rad} / \mathrm{s})$ \\
\hline loaded torque & $\tau^{\text {load }}$ & 12.0 & $\mathrm{~N} \mathrm{~m}$ \\
\hline
\end{tabular}

THD is approximately $9 \%$. At this condition, the reduction ratio of the switching frequency is $8.78 \%$. Based on the dqaxis current responses of VIRTM, it is verified that the amplitude of the dq-axis current ripple is almost constant size. This phenomenon implies the voltage vectors are outputted as long as possible by the hysteresis band.

Fig. 15 shows the frequency responses of each q-axis current response under the condition of $\mathrm{V} / \mathrm{f}$ control. By using VIRTM, the voltage integral error determines the switching timing, and the timing is variable. Therefore, the iqs of the proposed method include a wider range of frequency components, including low-frequency components, compared with DPWM.

Fig. 16 show experimental results of the voltage integral locus on condition of $\mathrm{V} / \mathrm{f}$ control and in the current THD is approximately $9 \%$. From the locus of voltage integral output of DPWM, DPWM outputs zero voltage vectors frequently. However, the duration of zero voltage vectors is short on the condition that the modulation factor is unity. Hence, VIRTM mainly outputs two non-zero voltage vectors. From the locus of voltage integral output of VIRTM, VIRTM eliminates those zero voltage vectors with short duration by the evaluation function. Moreover, VIRTM outputs only a voltage vector when the voltage integral output follows its reference by using only one voltage vector.

The performance comparison between DPWM and VIRTM on the condition of V/f control is shown in Fig. 17. Based on the experimental results, the effectiveness of VIRTM for reducing the switching frequency is confirmed in all experimental conditions. Moreover, the maximum reduction ratio of the switching frequency of VIRTM is $22.2 \%$ in that the current THD is approximately $11 \%$. Because of those results, this paper verifies that VIRTM reduces the switching frequency by comparing with DPWM in the feed-forward control system.

4.3 Feedback Control System Here, this paper verifies that VIRTM is applied for variable voltage reference, such as a feedback control system. Fig. 18 shows the velocity controller which is used to confirm responses of DPWM and VIRTM. Table 5 shows the operating conditions. This paper focuses on the switching frequency in steady state. In the comparative experiment, the parameters $f_{c a r}$ and $\Delta \int v \mathrm{~d} t$ are changed like the experiment of the feed-forward control.

The output of current PI controller is the original voltage reference. In order to follow the actual voltage to the ideal circle, VIRTM adjusts and modulates this voltage reference with the minimum switching numbers. Hence, the output voltage reference of VIRTM is not equal to the original voltage reference of current PI controller. In this case, the integrator of current PI controller should be compensated by using the anti-windup algorithm ${ }^{(18)}$. The purpose of the proposed system based on VIRTM is the ideal voltage control with the minimum switching numbers in steady state. In the numerical simulation results as shown in the appendix of this paper, the influence of the tested system is confirmed in comparison with the voltage control results with the anti-windup algorithm and the results without the anti-windup algorithm. As these results, since this paper confirms that the tested system has little influence on the difference of voltage reference, the anti-windup algorithm is not implemented in the experimental system of this paper.

Fig. 19 shows the experimental results in that the current THD is approximately $10 \%$. At this condition, the reduction ratio of the switching frequency by using VIRTM is $6.38 \%$. The characteristics of the current responses and voltage vectors are the same as that of the experimental results in the feed-forward control system. VIRTM eliminates the voltage vector with a short duration and achieves the switching frequency reduction. Moreover, the dq-axis current responses of VIRTM have ripple which is almost constant in size.

Fig. 20 shows the frequency responses of each q-axis current response under the condition of velocity control. Using VIRTM, the voltage integral error determines the switching timing. Thus, the frequency components are spread out, similar to that of on condition V/f control shown in Fig. 15a.

Fig. 21 show the voltage integral locus in velocity control and the current THD is approximately $10 \%$. Voltage integral locus of DPWM and that of VIRTM have a little vibration by the feedback system. However, those loci have the same tendency as the locus of V/f control. VIRTM outputs a few zero voltage vectors and reduces the switching frequency reduction.

Fig. 22 shows the experimental performance comparison between DPWM and VIRTM. In all investigated conditions, the switching frequency of VIRTM is lower than that of DPWM. Therefore, the effectiveness of VIRTM is confirmed. Moreover, the maximum reduction ratio of the switching frequency by using VIRTM is $17.8 \%$ in that the current THD is approximately $13 \%$. Based on those results, this paper confirms that VIRTM reduces the switching frequency by comparing with DPWM in also the feedback control system. 


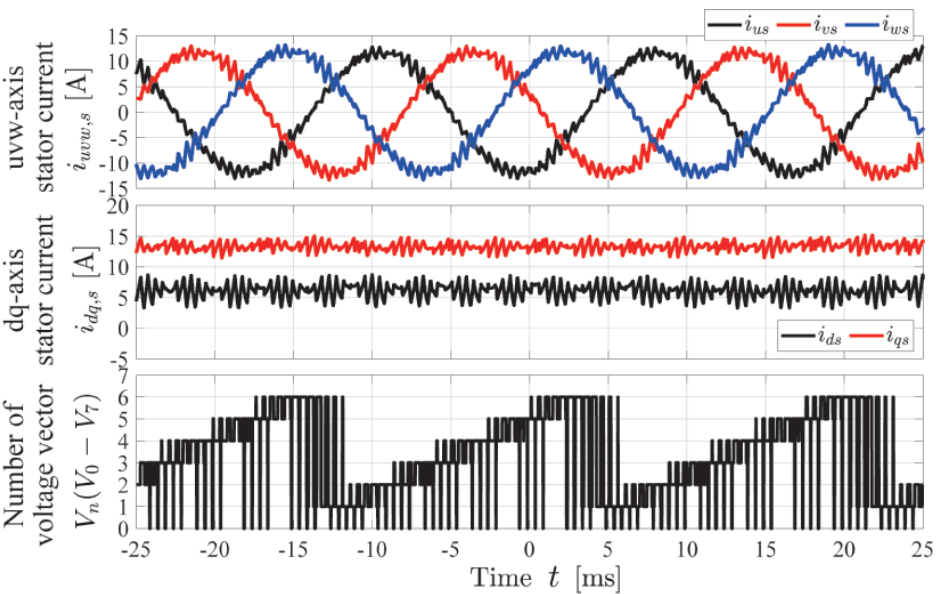

(a) Responses modulated by DPWM
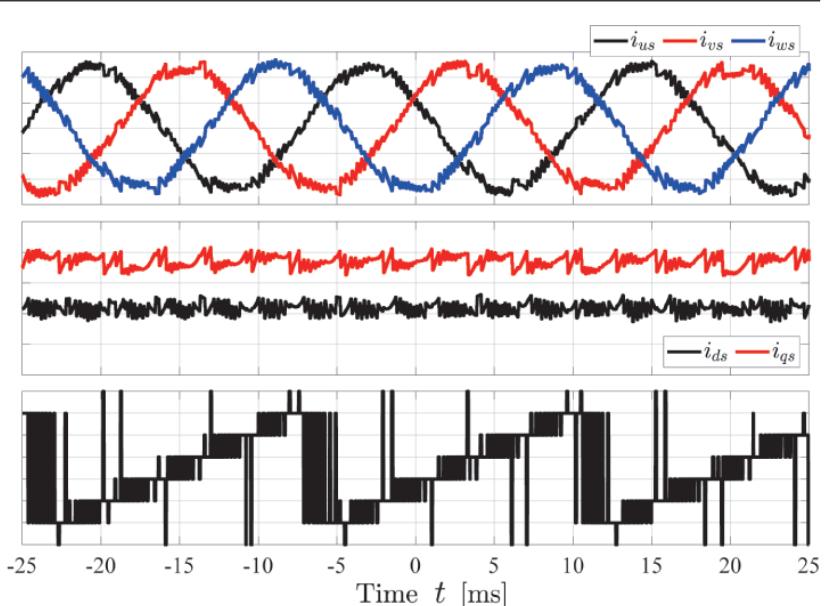

(b) Responses modulated by VIRTM

Fig. 14. Experimental results of responses waveforms of DPWM and VIRTM on condition of V/f control with rated load and modulation factor $=1.0$.

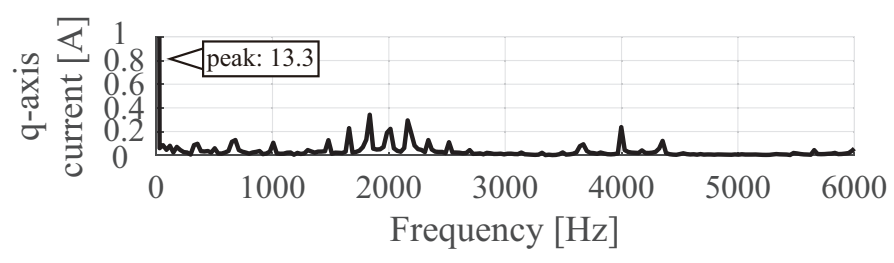

(a) Frequency response on condition of DPWM.

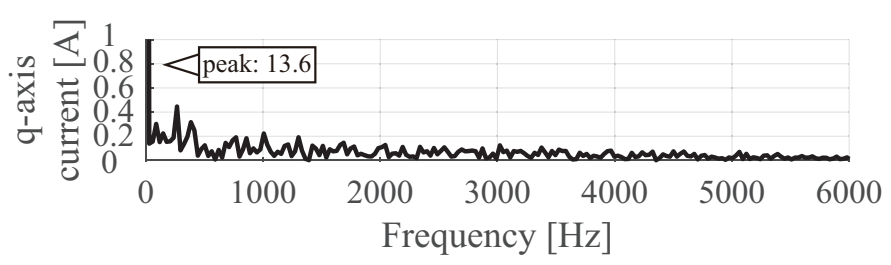

(b) Frequency response on condition of VIRTM.

Fig. 15. Experimental frequency responses of q-axis current of each modulation method on condition of V/f control.

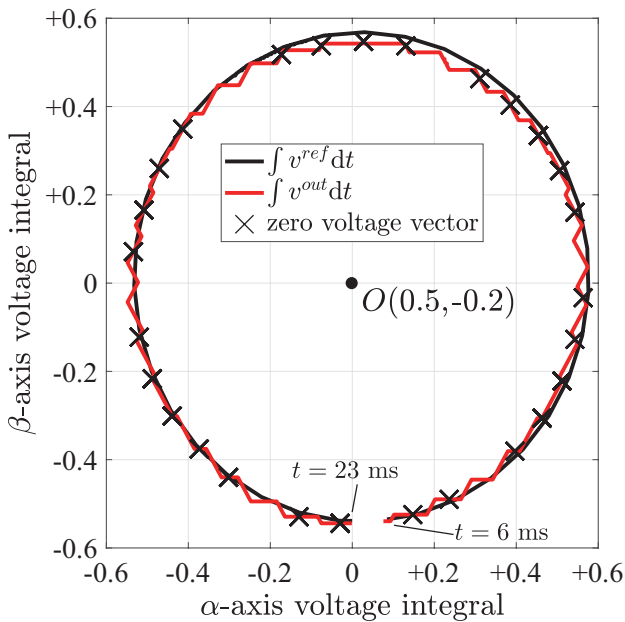

(a) Responses modulated by DPWM.

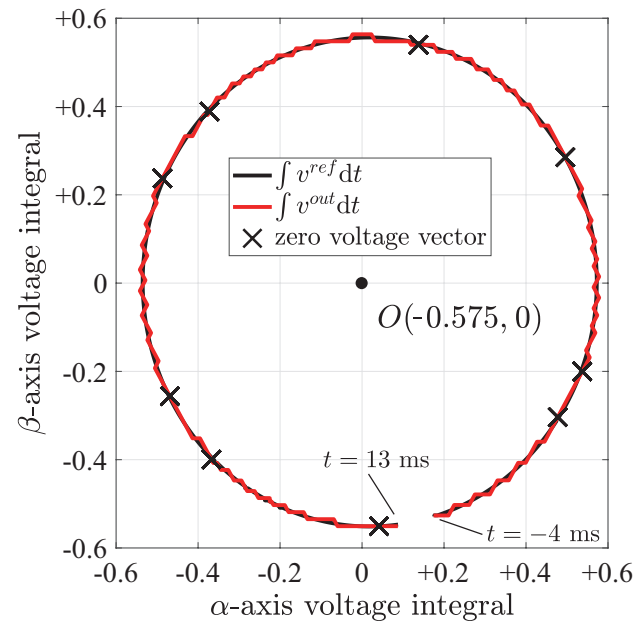

(b) Responses modulated by VIRTM.

Fig. 16. Experimental results of voltage integral locus of DPWM and VIRTM on condition of V/f control with rated load and modulation factor $=1.0$.

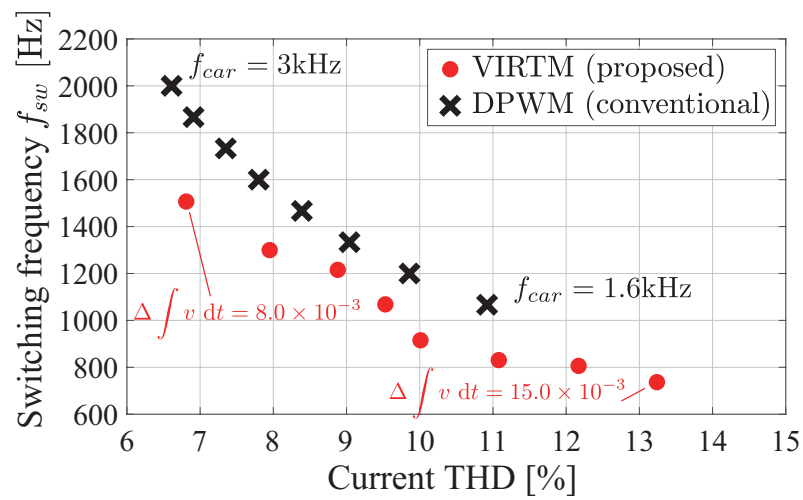

Table 5. Operation condition for velocity control.

\begin{tabular}{cc|rl}
\hline \hline Parameter & Symbol & Specification & Unit \\
\hline \hline rotor angular velocity reference & $\omega_{r m}^{r e f}$ & 180 & $\mathrm{rad} / \mathrm{s}$ \\
\hline rotor d-axis flux reference & $\psi_{d r}^{r e f}$ & 0.45 & $\mathrm{~Wb}$ \\
\hline loaded torque & $\tau^{\text {load }}$ & 12.0 & $\mathrm{~N} \mathrm{~m}$ \\
\hline \hline bandwidth of velocity control & $\omega_{v c}$ & 50 & $\mathrm{rad} / \mathrm{s}$ \\
\hline bandwidth of DOB & $\omega_{d o b}$ & 50 & $\mathrm{rad} / \mathrm{s}$ \\
\hline bandwidth of flux control & $\omega_{f c}$ & 20 & $\mathrm{rad} / \mathrm{s}$ \\
\hline bandwidth of current control & $\omega_{c c}$ & 1000 & $\mathrm{rad} / \mathrm{s}$ \\
\hline \hline
\end{tabular}

Fig. 17. Experimental performance comparison results between DPWM and VIRTM on condition of V/f control with rated load and modulation factor $=1.0$. 


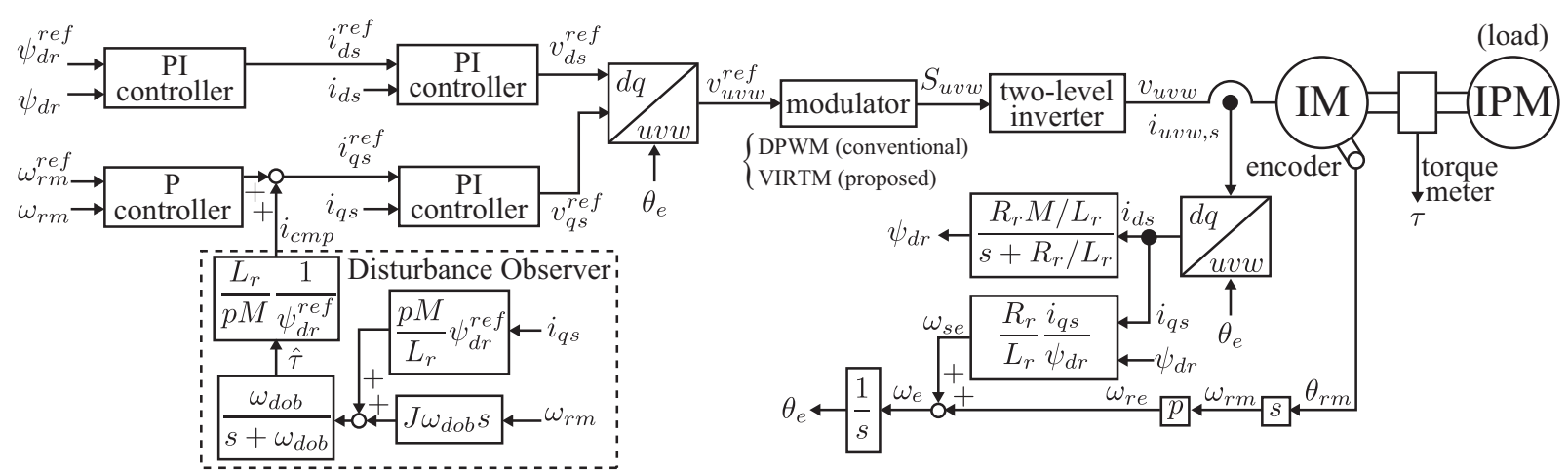

Fig. 18. Block diagram of velocity control.

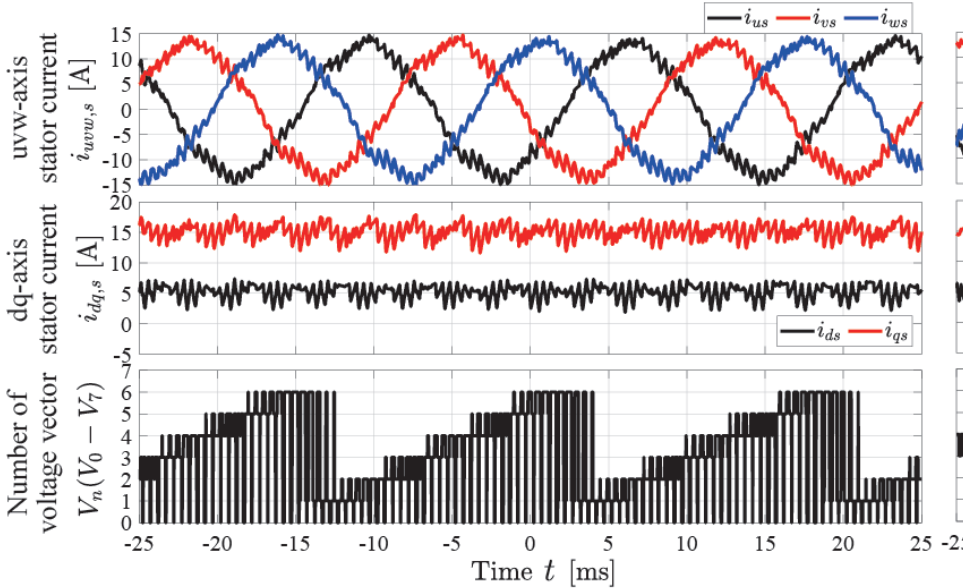

(a) Responses modulated by DPWM.

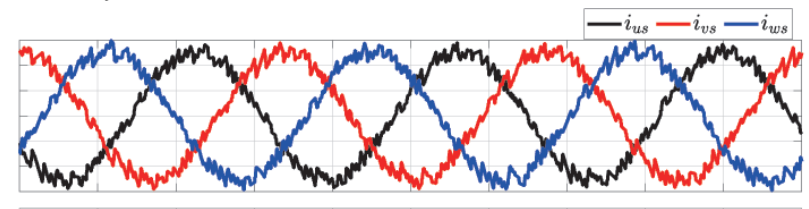

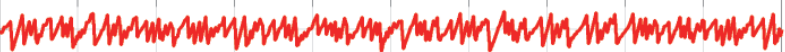

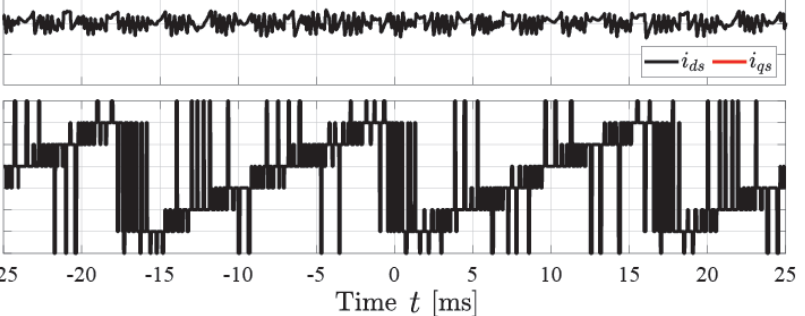

(b) Responses modulated by VIRTM.

Fig. 19. Experimental results of responses waveforms of DPWM and VIRTM on condition of velocity control with rated velocity and rated load.

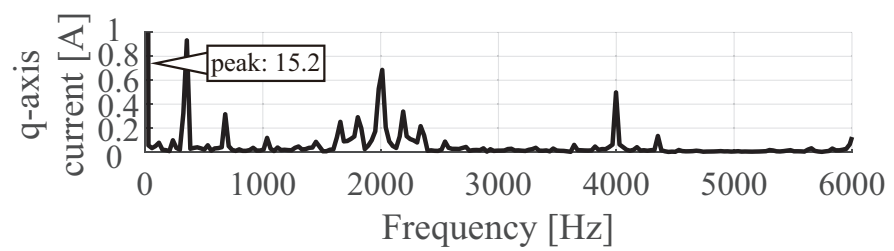

(a) Frequency response on condition of DPWM.

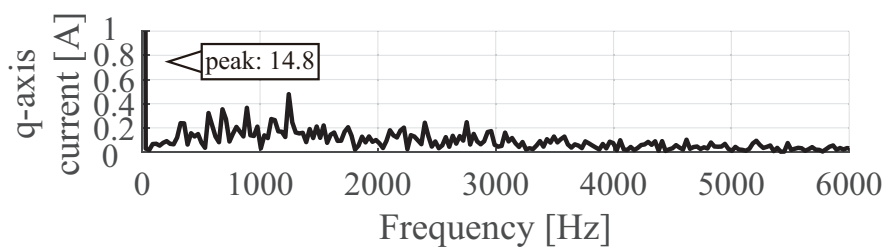

(b) Frequency response on condition of VIRTM.

Fig. 20. Experimental frequency responses of q-axis current of each modulation method on condition of velocity control

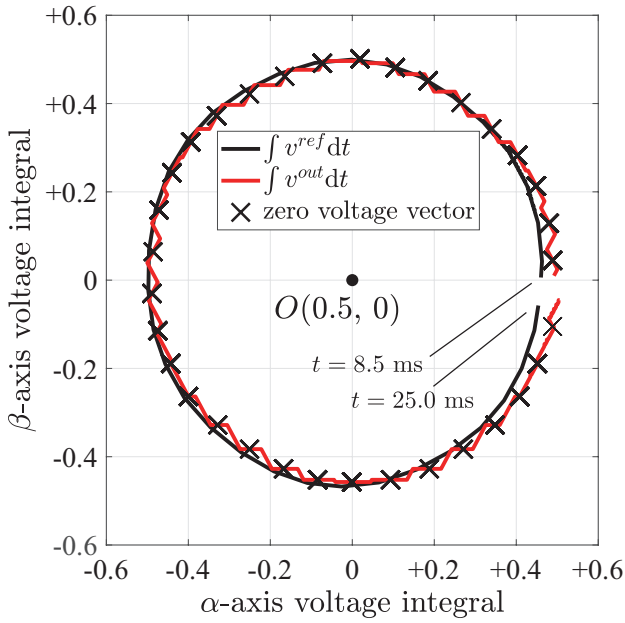

(a) Responses modulated by DPWM.

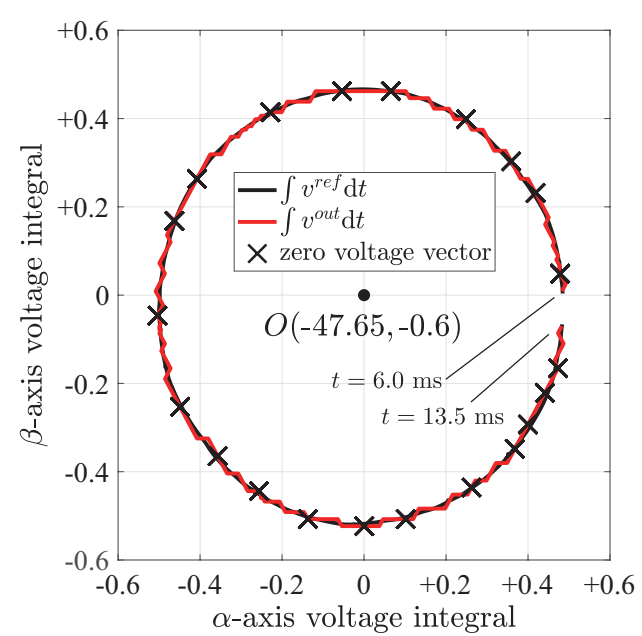

(b) Responses modulated by VIRTM.

Fig. 21. Experimental results of voltage integral locus of DPWM and VIRTM on condition of velocity control with rated load and modulation factor $=1.0$. 


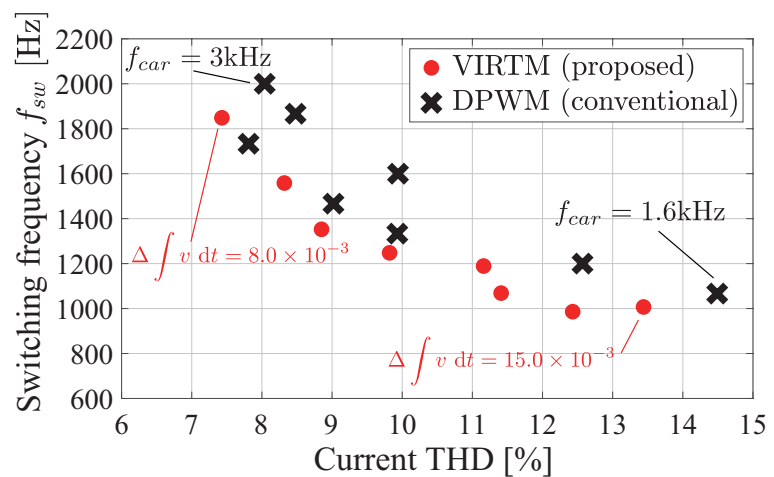

Fig. 22. Experimental performance comparison results between DPWM and VIRTM on condition of velocity control with rated velocity and rated load.

\section{Conclusion}

This paper proposes the VIRTM as a simple voltage modulation method. The proposed method simply reduces the switching frequency regardless of the motor parameters and control system characteristics for high-efficiency inverter control. This paper theoretically analyzes that the duration of the switching state is a factor for reducing the switching frequency. Based on the analysis, the proposed method optimizes the duration and the switching count by using the evaluation function. Through experimental results, this paper verifies that the proposed method is effective for reducing the switching frequency in feed-forward and feedback control systems. In the feed-forward control system, the maximum reduction ratio of switching frequency by the proposed method is $22.2 \%$, and in the feedback control system, the maximum reduction ratio of switching frequency by the proposed method is $17.8 \%$. The experimental results also confirm that the proposed method modulates the voltage reference regardless of the motor parameters and control system specifications. In the next step, the proposed VIRTM will be evaluated and discussed on both the transient response technique and the overmodulation method for the application of servo motors ${ }^{(18)(19)}$.

\section{References}

( 1 ) E. R. C. da Silva, E. C. dos Santos, and B. Jacobina, "Pulsewidth Modulation Strategies," IEEE Industrial Electronics Magazine, Vol. 5, No. 2, pp. 37-45, (2011).

( 2 ) K. Taniguchi and H. Irie, "A Modulating Signal for Three-Phase Sinusoidal PWM Inverter," The transactions of the Institute of Electrical Engineers of Japan.B, Vol. 105, No. 10, pp. 880-886, (1985).

( 3 ) M. Meco-Gutierrez, F. Perez-Hidalgo, F. Vargas-Merino, and J. HerediaLarrubia, "A New PWM Technique Frequency Regulated Carrier for Induction Motors Supply," IEEE Transactions on Industrial Electronics, Vol. 53, No. 5, pp. 1750-1754, (2006)

( 4 ) A. Ruiz-Gonzalez, F. Vargas-Merino, m. meco gutierrez, J. Heredia-Larrubia, and F. Perez-Hidalgo, "Pulse width modulation technique with harmonic injection in the modulating wave and discontinuous frequency modulation for the carrier wave to reduce vibrations in asynchronous machines," IET Power Electronics, Vol. 1206 , (2019)

( 5 ) F. Vargas-Merino, M. Meco, J. Heredia-Larrubia, and A. Ruiz-Gonzalez, "Low Switching PWM Strategy Using a Carrier Wave Regulated by the Slope of a Trapezoidal Modulator Wave," Industrial Electronics, IEEE Transactions on, Vol. 56, pp. 2270 - 227407, (2009)

( 6 ) A. Hava, R. Kerkman, and T. Lipo, "A high-performance generalized dis- continuous PWM algorithm," IEEE Transactions on Industry Applications, Vol. 34, No. 5, pp. 1059-1071, (1998).

( 7 ) J. Acero, D. Navarro, L. A. Barragan, I. Garde, J. I. Artigas, and J. M. Burdio, "FPGA-Based Power Measuring for Induction Heating Appliances Using Sigma-Delta A/D Conversion," IEEE Transactions on Industrial Electronics, Vol. 54, No. 4, pp. 1843-1852, (2007).

( 8 ) E. Dallago and G. Sassone, "Advances in high-frequency power conversion by delta-sigma modulation," IEEE Transactions on Circuits and Systems I: Fundamental Theory and Applications, Vol. 44, No. 8, pp. 712-721, (1997).

( 9 ) A. Trzynadlowski, M. Bech, F. Blaabjerg, and J. Pedersen, "An integral space-vector PWM technique for DSP-controlled voltage-source inverters," IEEE Transactions on Industry Applications, Vol. 35, No. 5, pp. 1091-1097, (1999).

(10) J. Nieznanski, A. Wojewodka, and R. Chrzan, "Comparison of vector sigmadelta modulation and space-vector PWM," 2000 26th Annual Conference of the IEEE Industrial Electronics Society (IECON 2000), Vol. 2, pp. 1322 1327, (2000).

(11) T. N. Mir, B. Singh, and A. H. Bhat, "Predictive Delta Sigma Modulation for Three-Phase to Three-Phase Matrix Converters," IEEE Transactions on Power Electronics, Vol. 35, No. 1, pp. 968-976, (2020).

(12) T. Geyer, G. Papafotiou, and M. Morari, "Model Predictive Direct Torque Control-Part I: Concept, Algorithm, and Analysis," IEEE Transactions on Industrial Electronics, Vol. 56, No. 6, pp. 1894-1905, (2009).

(13) T. Hiwatari, K. Ohishi, Y. Yokokura, H. Kada, S. Sano, and A. Satake, "Fast Torque Response and Reduced Pulse Width Modulation Switching Frequency Based on Model Predictive Direct Torque Control and Selective Harmonic Elimination," IEEJ Journal of Industry Applications, Vol. 7, No. 5, pp. 431-440, (2018).

(14) J. Holtz, "Advanced PWM and Predictive Control-An Overview," IEEE Transactions on Industrial Electronics, Vol. 63, No. 6, pp. 3837-3844, (2016).

(15) Y. Araki, K. Abe, K. Ohishi, Y. Yokokura, J. Sano, K. Kobayashi, and T. Kashihara, "Harmonic Current Reduction Control Based on Model Predictive Direct Current Control of IPMSM and Input Grid Circuit," IEEJ Journal of Industry Applications, Vol. 9, No. 1, pp. 17-26, (2020).

(16) P. Karamanakos, E. Liegmann, T. Geyer, and R. Kennel, "Model Predictive Control of Power Electronic Systems: Methods, Results, and Challenges," IEEE Open Journal of Industry Applications, Vol. 1, pp. 95-114, (2020).

(17) Y. Iwaji and S. Fukuda, "A PWM Pulse Pattren Optimization Method Using Carrier Frequency Modulation," IEEJ Transactions on Industry Applications, Vol. 111, No. 7, pp. 523-530, (1991) (in Japanese).

(18) K. Ohishi and T. Mashimo, "Design Method of Digital Robust Speed Servo System Considering Output Saturation," IEEJ Transactions on Industry Applications, Vol. 119, No. 1, pp. 88-96, (1999) (in Japanese).

(19) K. Takahashi, K. Ohishi, and T. Kanmachi, "Space Vector Modulation Inverter Considering Acceleration Torque and Voltage Saturation for Speed Servo System," IEEJ Transactions on Industry Applications, Vol. 129, No. 10, pp. 1013-1014, (2009) (in Japanese).

\section{Appendix}

\section{Effects of Anti-Windup Control on Condition of VIRTM}

This simulation verifies the difference of voltage integral locus with and without the anti-windup control when the bandwidth of current control is low. In this simulation, the velocity control that shown in Fig. 18. As the current controller, the current controller that has anti-windup control shown in app. Fig. 1 is used.

app. Fig. 2 shows voltage integral loci by using the current controller with the anti-windup control and without the antiwindup control. Here, the specifications of controller and simulation condition are the same with Table 5. Based on the results, the difference of voltage integral locus with and without the anti-windup control is scarcely confirmed.

\section{Performance of Each Operation Point}

To confirm the effectiveness of VIRTM on some motor operation points, this paper simulated the performance of DPWM and VIRTM under the condition of velocity control with the rated velocity or rated power. These simulations are tested on Typhoon HIL 602+ (Hardware In the Loop, HIL) 


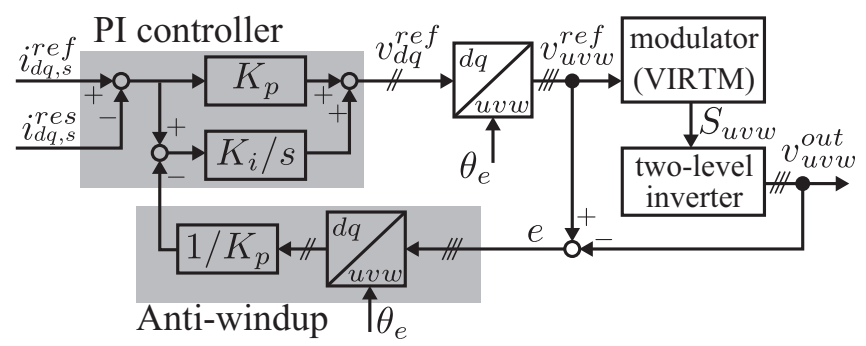

app. Fig. 1. Block diagram of current control with antiwindup control.

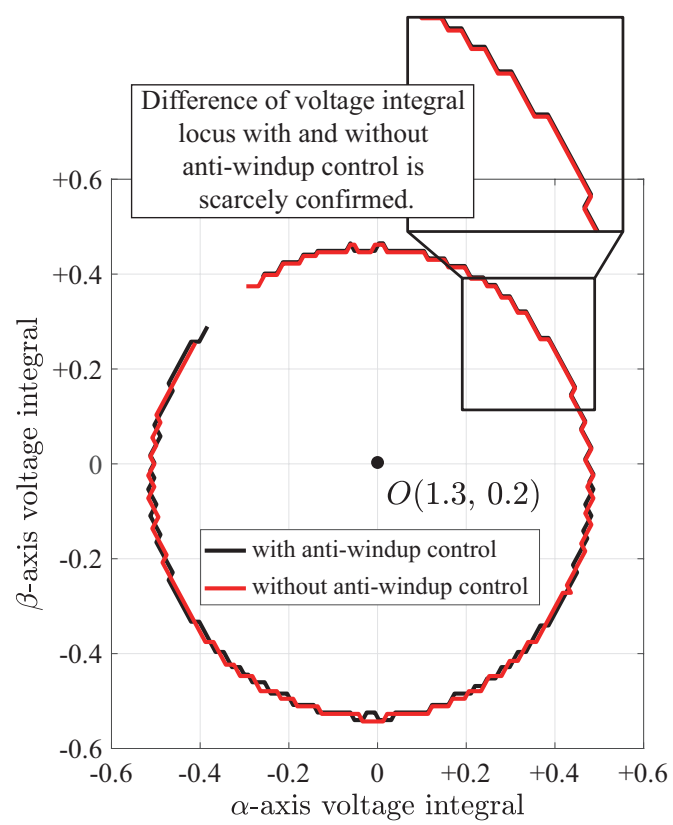

app. Fig. 2. Numerical simulation results of loci of voltage integral output of VIRTM on condition of velocity control with rated velocity and rated load.

made by Myway Plus Corporation. app. Fig. 3 shows the simulation environment. HIL performs is used as the experimental environment.

app. Fig. 4a shows the numerical simulation performance comparison results under the condition that the load condition is changed during the rated velocity. Based on these results, the effectiveness of VIRTM is confirmed under the conditions of a half load or more. The effectiveness of VIRTM is larger when the load torque is large. This is because operation with a high load requires a high modulation factor. Then, the output of the zero voltage vector has a shorter duration, and VIRTM effectively eliminates those outputs with a short duration.

app. Fig. $4 \mathrm{~b}$ shows the numerical simulation performance comparison results for the velocity condition changed during the rated power. Based on these results, the effectiveness of VIRTM is confirmed. Therefore, VIRTM reduces the switching frequency not only for the rated velocity operation, but also for the flux-weakening operation.

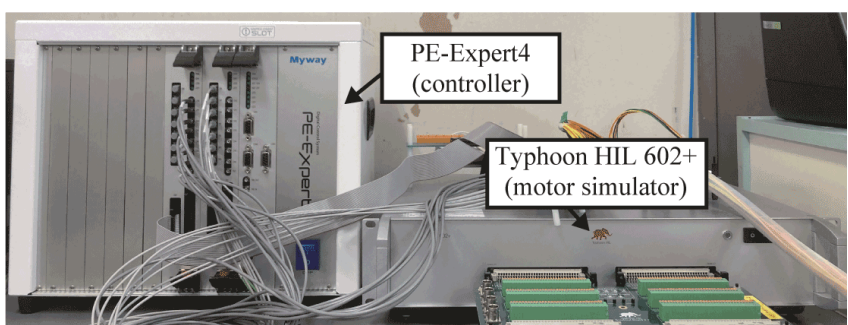

app. Fig. 3. Numerical simulation environment by using Typhoon HIL 602+.

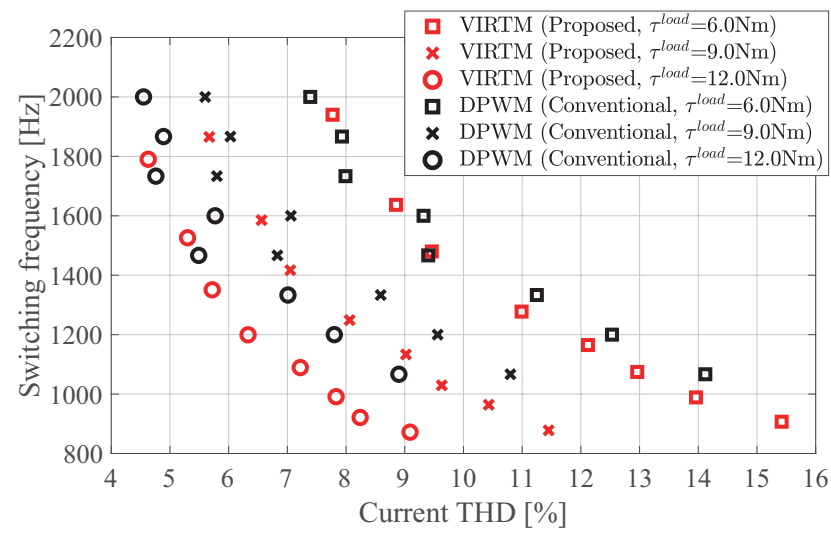

(a) Changing the load condition during rated velocity.

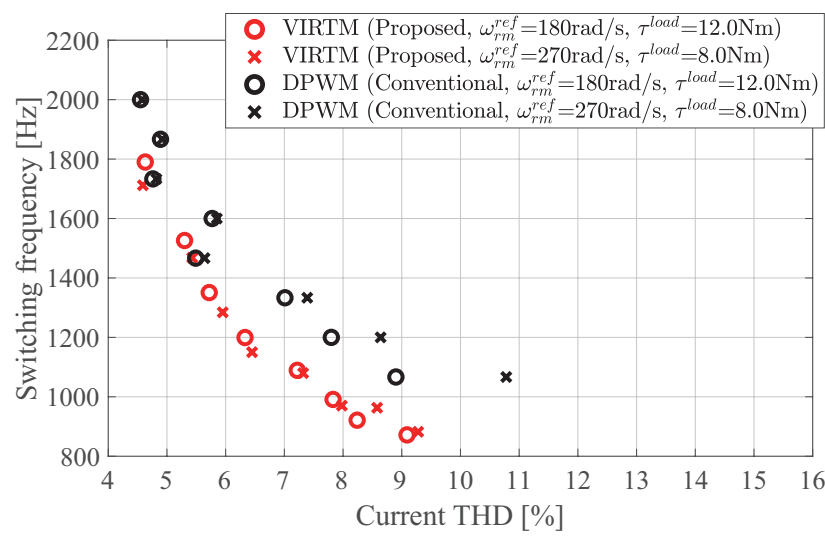

(b) Changing the velocity condition during rated power.

app. Fig. 4. Numerical simulation performance comparison results of each modulation method on condition of velocity control.

Yuto Kobayashi (Student Member) received B.S. degree in Electri-

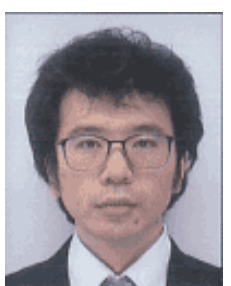
cal, Electronics and Information Engineering from Nagaoka University of Technology, Japan in 2020. Now, he is a candidate of the Ph.D degree in Science of Technology Innovation. His research interests include motor drive. He is a student member of the Institute of Electrical Engineers of Japan (IEEJ). 
Kiyoshi Ohishi (Fellow) received the B.E., M.E., and Ph.D. degrees in electrical engineering from Keio University, Yokohama, Japan, in 1981, 1983, and 1986, respectively. From 1986 to 1993, Prof. Ohishi was an Associate Professor with Osaka Institute of Technology, Osaka, Japan. Since 1993, he has been with Nagaoka University of Technology, Niigata, Japan. He became a Professor in 2003. His research interests include motion control, mechatronics, robotics and power electronics. He received twice "IEEJ Distinguished Paper Award" from IEEJ in 2002 and 2009, respectively. He is an IEEE Fellow member from 2015. He is a Senior AdCom Member of IEEE IES Society from 2016, and he was an AdCom Member (elected) of IEEE IES Society for 12 years from 2004. He received the Outstanding Paper Awards at IECON' 85 and Best Paper Awards at IECON' 02, IECON' 04 from the IEEE Industrial Electronics Society. He is a General chair of IEEE IECON2015, AMC2010, AMC2016 and AMC2018.

Yuki Yokokura (Member) received the B.E. and M.E. degrees in elec-

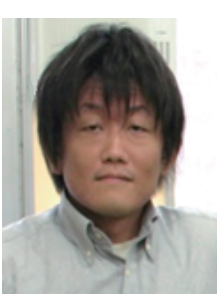
trical engineering from Nagaoka University of Technology, Niigata, Japan, in 2007 and 2009, respectively, and the Ph.D. degree in integrated design engineering from Keio University, Yokohama, Japan. He was a Visiting Fellow at Keio University, and a Postdoctoral Fellow at Nagaoka University of Technology in 2011. Dr. Yokokura was a JSPS (Japan Society for the Promotion of Science) Research Fellow (DC2 and PD) from 2010 to 2011. He was an Assistant Professor with Nagaoka University of Technology from 2012 to 2020, and he has been an Associate Professor since 2020. His research interests include motion control, motor drive, power electronics, and real-world haptics.

Tenjiro Hiwatari (Member) received the B.E. and M.E. degree in

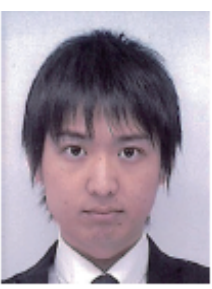
Electrical, Electronics and Information Engineering from Nagaoka University of Technology, Japan, in 2016 and 2018, respectively. He joined Advanced Technology R\&D Center of Mitsubishi Electric Corporation in 2018. He currently research of motor drive in Advanced Technology R\&D Center of Mitsubishi Electric Corp., Amagasaki, Japan.

Akira Satake (Member) received the B.E. degree from The Univer-

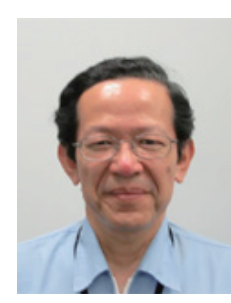
sity of Tokyo, Japan, in 1985 . He joined Industrial System Laboratory of Mitsubishi Electric Corporation in 1985. His research focused on motor drive technologies, including controls for mechatronics components and power-electronic circuits. He received R\&D100 awards with sensor-less servo drive system in 2014. He is currently a chief engineer for research of motor drive in Advanced Technol-

agasaki, Japan. ogy R\&D Center of Mitsubishi Electric Corp., Am- 